\title{
16 Englishization as trap and lifeline
}

\author{
Philippe Van Parijs
}

\begin{abstract}
In today's Europe, internationalization is driven by three mutually reinforcing mechanisms: EU funding, rankings, and commodification. And it calls for Englishization because in most cases the learning of the local language by foreign students is too much to expect, whereas a powerful bottom-up 'maximin' dynamics generates such a wide dissemination of English that prior knowledge of it can be taken for granted. Is Englishization a problem? Of course it is, for several reasons. Yet there is no responsible path away from internationalization, nor any reasonable hope of achieving it without Englishization. We must therefore aim at a fragile balance between giving enough place to English not to fall behind and protecting local languages against slow agony.
\end{abstract}

Keywords: Englishization, internationalization, maximin principle, network power, contestation

\section{$1 \quad$ Englishization - a problem?}

Is the Englishization of Europe's higher education a problem? And if it is a problem, is there anything that can and should be done about it that does not create more harm than it cures? ${ }^{1}$

1 The present concluding essay is heavily indebted to the very instructive essays collected in this volume and to useful feedback by René Gabriëls, Robert Wilkinson and Filippo Contesi. It draws on the approach to linguistic issues presented in Van Parijs (2000), and more fully in Van Parijs (2011) (German edition published by Suhrkamp, 2013; Dutch edition by Lannoo, 2015) and discussed in De Schutter and Robichaud (2015).

Wilkinson, Robert, and René Gabriëls (eds), The Englishization of Higher Education in Europe. Amsterdam, Amsterdam University Press 2021 DOI: 10.5117/9789463727358_CH16 
Before addressing these questions, it is prudent to first ask whether the Englishization of higher education - understood as an increase in the share of higher education courses or entire programmes using English as the medium of instruction in European universities - is a fact. Reading the contributions to this very instructive volume leaves no doubt: there has been, over the last two or three decades, a strong and accelerating trend that deserves to be called 'Englishization', but with huge differences. It tends to be more pronounced in countries with 'small' languages than in countries with 'big' languages, at master's and doctorate levels more than at bachelor's level, in certain disciplines like management or engineering more than in medicine or law and in research universities more than in institutions aiming to train highly skilled professionals for the local labour market.

Is Englishization a problem? It certainly is if, firstly, the quality of education suffers badly as a result of transmission and interaction being hampered by a poor command of English by teachers and/or by students, and possibly also as a result of having to use foreign teaching material ill-suited to local needs. Secondly, it is a problem to the extent that it makes access to higher education more difficult for socially less advantaged students, in particular many of those with an immigrant background, or confines them to a downgraded lower-tier higher education sector operating exclusively in the local language. It is a problem, thirdly, to the extent that it contributes to the deepening gap between academia and society at large by inhibiting the development of a lexicon that keeps track, in the local language, of scientific advances and by hindering the flow of knowledge and ideas between universities and the rest of society. Finally, it is regarded by many as a major problem because it weakens the status and grip of the national language, previously the exclusive medium of instruction, as an essential ingredient of the identity of the nation and of the glue that turns a population into a community. For all four of these reasons, Englishization runs the risk of gradually unravelling what European universities had laboriously achieved a couple of centuries earlier by getting rid of Latin in favour of the local vernaculars.

If Englishization is problematic in so many ways, one may wonder why it is progressing at such a rapid pace. In order to understand this, it is essential - as we see being done throughout this volume - to link the Englishization of higher education with its internationalization, here understood as an increase in the share of foreigners in the student 
population of the higher education institutions of a country. ${ }^{2}$ Before turning to that link, however, it is useful to note that these two processes are not necessarily coupled.

Firstly, there can be high degrees of internationalization without Englishization. Think, for example, of Rome's Latin-medium Gregorian university; of the USSR's Russian-medium university system, with over $10 \%$ of its students coming from friendly countries close by or far away; of today's Russia attracting Russophones from countries that used to be part of the USSR; of France, Spain or Portugal attracting many students from former colonies that kept the colonial language in much of their own education systems; or of Francophone and Germanophone universities attracting students from countries in which French or German was, until not so long ago, the first foreign language for many pupils.

Secondly, there can also conceivably be high degrees of Englishization with no internationalization. The authorities of a country may regard higher education in English as useful for their own population despite English not being the local native language. This is the case on a massive scale, and not only for higher education, throughout the Commonwealth. It is also the case, on a more modest scale, in much of the rest of the world, with $\mathrm{CLIL}^{3}$ instruction in English meant to better prepare local students for a career in scientific research or international business.

Thus, Englishization and internationalization must be distinguished, but it is the close link between them in today's Europe that we must scrutinize in order to better identify the source of what is experienced as a problem and the best way to address it.

\section{Trapped in internationalization}

In order to understand the joint forward march of internationalization and Englishization, one may wish to depict European higher education as a battlefield between ideologies and the material interests associated with them. However, I believe it is more illuminating to identify and describe the mechanisms that underlie the current trends and explain their irresistibility,

2 The internationalization of the university staff is closely associated with the internationalization of the student population only in case of Englishization or, more generally only when a lingua franca different from the local language is adopted as the medium of instruction. When foreign students are attracted from former colonies or satellite states, for example, there is no strong pressure for the staff to internationalize.

3 Content and language integrated learning. 
perhaps even their irreversibility. All of them are neatly illustrated in the instructive country case studies gathered in this volume. There are, first, three very different mechanisms that trap universities in a process of internationalization, and next three mechanisms that, combined, are bound to turn internationalization into Englishization.

Why do universities internationalize? A first cause is demographic. As international migration proceeds without leading systematically to the naturalization of immigrants - especially when they are coming from another member state of the European Union (EU) - the share of foreign citizens in the student population of our universities can be expected to slowly increase. A second cause might be called scientific. At least for advanced specialized degrees, it is often healthy for students to bear the costs of expatriation in order to find abroad what they cannot find at home. The third cause is rather educational: it can be very valuable for local students to develop personal relationships with people who grew up in different material and cultural contexts thanks to 'internationalization at home', the active hosting of foreign students. But over above these three 'natural' causes, there are three other causes, each rooted in a distinct mechanism, that can end up 'trapping' universities in a process of internationalization that they would not have spontaneously chosen.

The most obvious such mechanism is the funding of student mobility by the European Union, from the massive Erasmus programme established over three decades ago to the recent European Universities Initiative. The rationale is plausible enough: if you want to build a real European community, its future elite at least must have a taste of education and life in other member states and establish friendships outside their national community at an early stage in their adult lives. When quite a large amount of money is made available for the benefit of one's students in exchange for welcoming students from other universities across Europe, it is hard for university authorities to turn it down, despite the considerable administrative and pedagogical burdens this unavoidably involves.

Slightly less visible and far more general is a second mechanism: university rankings. Influential rankings such as the annual QS World University Ranking give significant weight to the share of foreigners among both students and staff. The rationale behind this simple criterion is plausible enough. How many foreigners choose to study at a university or to work for it provides a very rough but objective index for its attractiveness and hence its presumed quality. The degree of internationalization also enters such rankings indirectly through the component of the index that relies on academics mentioning what they regard as the best departments in their 
field. If your university hosts many foreign students, it is more likely to be positively remembered by your foreign colleagues when they answer the survey. Every academic realizes how arbitrary these rankings are, but no one can deny their impact, not least through the echoes they trigger in the national media. Those who criticize them when their universities do badly are discredited as bad losers. And those whose universities happen to do well by the standards of some ranking can seldom resist the temptation to boast about it. As the degree of internationalization is one of the factors affecting the rankings that is most directly under the control of universities, it is hard for university authorities not to let this affect their admission policies, irrespective of whether it is in their interest to attract more foreign students for other reasons. The sheer prestige of featuring high up in the rankings suffices as a driving force.

The first mechanism had to do with accessing public funding, the second one with gaining recognition. Only the third one is directly connected with the 'commodification' of higher education, its subjection to a market or a quasi-market. In most countries, how much money universities receive for their teaching activities is closely related to the number of students they attract, either through the fees paid by the students or their parents or through the per capita subsidies paid by the government (or both). Due to economies of scale, it is then often in the material interest of a university to attract as many students as possible. Moreover, even when it is not - because the marginal cost exceeds the marginal revenue - university authorities tend to take pride in growing enrolments. If student choice is not narrowly constrained on a geographical, linguistic, or religious basis, competition for market shares can already be intense within countries. But as soon as studying abroad is viewed as a real possibility by students, competition starts operating on a much larger scale. The harmonization of degree structures triggered by the 1999 Bologna declaration and the Bologna process it launched (which now involves 48 countries) and the mutual recognition of degrees realized step by step within the EU increased considerably the real choice for students and thereby, inseparably, the (quasi-)market pressure on universities. As a result, these had arguably no option but to try to internationalize, if only in order to compensate for their own pool of students being depleted by foreign attraction and in several countries also by a downward local demographic trend. As international mobility intensifies, universities that do not enter the international market game will sink.

Once this third mechanism becomes significant, the other two gain in importance: getting more EU funds for student exchanges and achieving a better position in international rankings are precious assets in the 
international competition for students. This makes clear enough why university authorities tend to promote internationalization. If the studies of foreign students were entirely covered by their fees, attracting them would also unambiguously be in the material interest of the national authorities. But this is far from being the case, especially for EU students, who enjoy the same fee regime as local ones. Whether governments can expect an overall net material benefit from internationalization despite an immediate net cost will then depend on how much foreign students spend on local goods and services and on how likely they are to remain in the country and contribute to its economy after completing their studies. For this reason, and also for other reasons we shall turn to after discussing the connection with Englishization, there is no pre-established harmony between what governments and universities are inclined to push for.

\section{Stuck with English}

Next then, what accounts for the close association between the push for internationalization and the push for Englishization? As pointed out above, you can in principle have the former without the latter. All programmes could be organized in the local language and foreign students who do not know that language before coming would be expected to learn it soon after their arrival to an extent sufficient for attending classes and taking exams. This would require providing good intensive language courses free of charge. Even so, the investment by each student would be considerable, especially if the language to be learned is very different from their own native language and if they had little exposure to it before their arrival. The cost of this investment will easily be found prohibitive if the local language is not a widely spoken one and if the student does not expect to stay more than a short period. In most countries, therefore, sticking to this strategy does not have the slightest chance of bringing about the internationalization universities are eager to achieve. The alternative consists in offering the programme in a language - if there is one - that is already far more widely known by potential foreign recruits and/or which these potential recruits are keen to learn better. It is then the local teachers rather than the foreign students who will have to bear the (time) cost of the linguistic investment, and if the linguistically competent supply from local resources proves insufficient, teaching staff can also be recruited from abroad.

It so happens that there is now such a language. Competence in English has been spreading very quickly, from cohort to cohort, throughout 
continental Europe and beyond, and it is bound to keep spreading. Why? Not because of some opaque neo-liberal or imperialistic plot, but because of the mutual reinforcement of two very simple and ubiquitous mechanisms. One is rooted in the concern to be understood with as little trouble as possible by those with whom we are communicating. Among the various languages we could conceivably use in a particular conversation, this leads us to pick systematically, not the language best known by the majority or best known on average, but the maximin language: the language best known by the person who knows it least well. And given that it is by practising a language that we maintain and develop our linguistic competence, competence in the language that features in maximin position keeps spreading. To illustrate, just reflect on the following fact reported to me by a Dutch language teacher at the University of Lille (in Northern France): he was delighted to have been able to send his students for a semester to the University of Leiden, pleased to hear that they had had a good time, but flabbergasted to discover on their return that their Dutch was hardly better than before, whereas their oral English had made impressive progress.

The anticipation of a language featuring in maximin position and hence being used triggers a further mechanism: deliberate investment in the learning of a language through language classes and in other ways. This mechanism is an instance of 'network power', analogous to what is going on when we or our institutions purchase Word or PowerPoint because many others with whom we wish to interact have done so before. It is the (correct) anticipation that English will be (increasingly) used in international linguistic encounters, active or passive, real or virtual, that makes countless students gladly devote to the improvement of their English an effort few would have dreamt of devoting to the learning of other languages. Further upstream, it is also that anticipation that makes pupils and their parents want the learning of English to be given high priority in all European schools.

This network power mechanism interacts with the maximin mechanism to produce a snowball effect. The more that is invested in the learning of English, the more often it features in maximin position, the more it is therefore used and thereby maintained and improved, and the more this further strengthens the incentive to invest in learning it. Needless to say, the choice to use English and to learn it comes generally - and regrettably - at the expense of the use and learning of other foreign languages. This twofold mechanism shapes the linguistic dynamics in society at large, but it has most deeply affected, discipline after discipline, the increasingly internationalized scientific communities, triggering the irreversible agony of countless journals and associations operating in languages other than 
English. It is also at work in the 'ripples' around internationalized higher education institutions and among the educated young adults who form the increasingly common pool of European universities. Higher education institutions that want to internationalize then face a simple choice: they must either stick to their own language and be prepared for a poor outcome at a high cost or go for an expansion of English-medium instruction.

The interlocking of these various mechanisms is what explains the strong combined pressure towards internationalization and Englishization at least at the meso level, the level of university authorities. Support at the macro level of governments, however, is far from self-evidently guaranteed, as several contributions to this volume document. First of all, as mentioned earlier, many foreign students come at an immediate cost for the local government, which the latter is by no means sure to recover. This is particularly the case if internationalization is achieved entirely or mainly thanks to Englishization. Foreign students then acquire little or no proficiency in the local language and therefore have only a low probability of joining the local labour market after their studies. To increase this probability, some countries have introduced an obligation to take a course in the local language. But if this is a light obligation, it will have no effect, and if it is a heavy one, it may be nearly as much of a deterrent as if the programme were offered in the local language. By offering English-medium instruction to all students, foreign or not, governments may even achieve exactly the opposite result: they may find that they are depleting rather than feeding the local market for high-skilled labour. English-medium instruction will result in many of the better local students becoming footloose and both able and tempted to find jobs elsewhere, especially in Anglophone countries.

Moreover, the national authorities may be more concerned with the vitality of the national language, culture, and identity than with the national economy. Especially in countries (or regions) with 'smaller' languages - and therefore with a lower expected stay rate among foreign students and a more acute feeling of linguistic vulnerability - macro-resistance is likely to temper meso-enthusiasm. As several countries illustrate, governments often impose restrictions on the development of English-medium instruction. For example, they require that parallel degrees should be organized in the local language or that the use of 'another language' than the local one should be strictly confined to cases in which the linguistic competence of the students requires it. Meso-activism, however, often circumvents macro hurdles. Universities tend to interpret restrictive legislation creatively so as to make themselves as attractive as possible to students with no prospect of learning the local language. 
Whereas it is in countries with 'small' languages that macro-resistance can be expected to be strongest, it is in countries with 'big' languages that one should expect greater resistance at the micro-level, the level of individual members of the academic or administrative staff. Other things equal, proficiency in English is inversely correlated with the spread of one's language. Therefore, it is in countries with 'bigger' languages that it will be more difficult to find teachers and administrators able - or disposed to become able - to operate in a language other than their own. In some of those countries pride in the national language may also nourish some macro-resistance (French, German and Russian used to be major academic languages). But in all of them, one can expect micro-resistance to temper meso-enthusiasm more than it does in countries with 'smaller' languages.

\section{Could and should Englishization be stopped?}

While the mechanisms listed above should suffice to explain the strong pressure towards internationalization and Englishization at a meso level - with frequent contagion to sectors of the macro and micro levels - the considerations spelt out at the end of the previous section should suffice to explain the tensions it keeps triggering at both the macro and micro level. I shall close this contribution by asking whether, in order to avoid these tensions and accommodate the underlying concerns, the twofold process of internationalization and Englishization could and should be stopped.

In order to switch off the pressure to internationalize, or at least to reduce it drastically, action would need to be taken at European level. The European Union would need to stop funding international student mobility. It would need to develop a sufficiently authoritative and influential ranking that attaches no weight, directly or indirectly, to the share of foreign students. And it would need to prevent governments from subsidizing foreign students, instead of forcing them to do so, as it does now in the case of EU students, at the same level as local students. Would that be desirable? It would certainly be a massive setback for the attempt to develop a mobile, truly European elite, inclined to think from a European and not just a national viewpoint. Moreover, it is in the interest of each member state and of the EU as a whole to keep hosting talented young people from around the world in their universities and their labour force, rather than letting British and American universities attract and retain them, thereby generating a massive brain drain in their favour. Let us bear in mind, for example, that Brexit deprived the EU of all of its universities usually ranked among the world's top 10 (3 
in the QS ranking) and most of those ranked among the top 100 (17 out of 27), and that the current net brain gain of the UK at the expense of EU27 is estimated to exceed 600,00o working-age people. Making EU universities less international in this context, one could argue, is nothing short of suicidal.

However, would it not be possible to emancipate the internationalization of European higher education from its connection with Englishization? Brexit itself seems to offer a unique opportunity to do so. With the UK out, why should English keep functioning as the lingua franca of European institutions, of Europe's transnational civil society and of its mobile youth gravitating around our universities? If internationalization could operate in another European language, the EU would stop shooting itself in the foot by contributing to the brain drain, as pointed out above, through preparing its own students for easy integration in the economic and social life of Anglophone countries. This hope is misplaced. Now that English is no longer the official language of one of the EU's big member states, it provides a more neutral medium in the EU context, and therefore a more appropriate instrument for that role - as it is also, for example, in India or in Nigeria. And in contrast with other parts of the world, opting for English in Europe does not carry with it the embarrassment of surrendering to a colonial language. Quite the contrary. English is a continental European language that was imposed on the population of Great Britain in two instalments - a Germanic one 1,500 years ago and a French one 1,00o years ago. It is high time that we should reappropriate it as our language and stop representing it, as some of our websites still do, by the Union Jack. In any case, no attempt to replace English by German or French as the EU's lingua franca has any chance of succeeding because of the resentment and resistance any such attempt would create among speakers of other languages and their governments, and above all because the bottom-up maximin dynamics that keeps strengthening the position of English will keep working throughout Europe and throughout the world.

There is, however, a more radical, yet (some would argue) less unrealistic alternative to Englishization than a shift to another European language. Could technological progress in voice recognition not enable us one day to dispense with English as a common medium of instruction, or indeed as a lingua franca? Once everyone can understand what is being taught in any language, there is no need for everyone to learn a common language. Unfortunately - or rather, fortunately - teaching does not consist in delivering unilaterally, under good acoustic conditions, a text that could also have been provided in writing. It consists in interacting in a lively, sometimes animated way, using proper names and neologisms, developing a micro-culture. And 
this purpose is still far better served even by somewhat broken English than by a stiffening technological prosthesis. This does not mean that the fast AI-driven improvement of translation software cannot make a difference. It will make it easier for non-native academics to produce publications and course material in good English and for students to use material in any language. This will make it possible to counteract one major negative side effect of the Englishization of higher education: the 'Americanization' of textbooks and more generally the use of course material designed for students living in the Anglophone part of the world. Technology can thus serve the purpose of producing a more diverse and more suitable course material - at least if not offset by the one-directional diffusion of massive open online courses (MOOCs) from Anglophone countries - but cannot provide a substitute for a shared language.

There is, therefore, no responsible path away from internationalization, nor any reasonable hope of achieving internationalization without Englishization. Owing to the four reasons (mentioned at the start) that this Englishization is a problem, this process will not be smooth. The tensions to which it leads are likely to remain or become passionate in some countries, though unlikely to reach the intensity of the conflicts unleashed by competition, often at all levels of education, between local languages and powerful neighbours: Spanish in Catalonia, Galicia, and the Basque countries, French in Flanders, Russian in the Ukraine and the Baltic states, Serbo-Croat in Slovenia or Kosovo.

Nonetheless, the tension is likely to become more severe because of the measures that will need to be taken in order to address the various problems mentioned. For example, in order to prevent the exclusion of less advantaged students from higher education or from its top tier, more English will need to be introduced at secondary level, including in the form of CLIL. In order to attract enough high-quality staff, universities will be under pressure to reduce the expectation of sufficient competence in the local language and consequently to switch to English, for maximin reasons, in internal communication and meetings. And in order to prevent higher education in English from feeding Anglophone countries with highly-skilled workers at low cost, non-Anglophone countries will need to make it more comfortable for the families of foreigners to get by without knowing the local language, including through the provision of English-medium public services and schools. These various 'ripples' entail a more profound invasion of English into the domain of the local language, easily amplified by the maximin dynamic. One can try to confine this invasion in 'linguistically free zones', while maintaining a 'linguistic territoriality principle' over the 
bulk of the territory. But the perimeter of this zone and the extent of the linguistic freedom allowed within it is most likely to remain the object of chronic contestation.

Is this, then, all we can expect: a fragile, conflict-ridden balance between giving enough place to English not to fall behind and protecting the local languages against domain loss and slow agony? Being in a position to avoid this uncomfortable balancing act is and will remain a major structural asset for Anglophone countries in general, and for their higher education sector in particular. It is this robust asset, together with its manifold consequences, that made Brexit, at the most fundamental level, a reasonable risk for the United Kingdom to take. The irreversible installation of English as the global lingua franca turns Anglophone territory into the 'ground floor of the world', into an attractor which can cherry-pick the most promising and talented among the many who want to enter. Is there a price to pay? Not by Anglophone territories but by Anglophone people: because of the maximin dynamic, the spreading of English as everyone else's second language will make it increasingly difficult for Anglophones to learn and maintain any other language. Our own advantage is the mirror image of this handicap. As English spreads, it will become ever easier for us non-Anglophones to become bilingual and enjoy the associated cognitive, aesthetic, and cultural benefits. These benefits will spread to our institutions and our countries if we academics resist the pull of the 'ground floor', if our affectio institutionis and/or our affectio societatis are sufficient to keep us, at least for the long term, on our linguistically so diverse continent. We are needed here for many reasons, but in particular to play the uncomfortable yet often gratifying role of go-betweens, of bridge builders between the irreversibly internationalized and Englishized academic community and our stubbornly distinctive local communities.

\section{References}

De Schutter, H., \& Robichaud, D. (Eds.) (2015). Linguistic justice. Van Parijs and his critics. Routledge.

Van Parijs, P. (200o). The ground floor of the world. On the socio-economic consequences of linguistic globalisation. International Political Science Review, 21, 217-233.

Van Parijs, P. (2011). Linguistic justice for Europe and for the world. Oxford University Press. 


\section{About the author}

PhILIPPE VAN PARIJs is a guest professor at the Universities of Louvain and Leuven and chairs the Brussels Council for Multilingualism. He was the founding director of Louvain's Hoover Chair of Economic and Social Ethics (1991-2016) and a regular visiting professor at Harvard and Oxford. 
